\title{
Social Mereology
}

\section{Katherine Hawley, University of St Andrews, kjh5@st-andrews.ac.uk}

\begin{abstract}
What kind of entity is a committee, a book group or a band? I argue that committees and other such social groups are concrete, composite particulars, having ordinary human beings amongst their parts. So the committee members are literally parts of the committee. This mereological view of social groups was popular several decades ago, but fell out of favour following influential objections from David-Hillel Ruben. But recent years have seen a tidal wave of work in metaphysics, including the metaphysics of parts and wholes. We now have the resources to rehabilitate the mereological view of social groups. I show how this can be done, and why we should bother.
\end{abstract}

\section{Keywords}

Social groups; membership; collectives; parthood; social ontology.

\section{Introduction}

What is a committee, a book group, or a band? What about a crowd, a population, or a social class? Each is a collective entity somehow made up of individual people, although the facts, attitudes, norms, and structures which ground such connections between individuals and collectives may be very diverse. But what is the metaphysical status of such collective entities? Are they particular or universal, singular or plural, abstract or concrete, simple or composite? 
In this paper, I defend the view that social groups are particular, singular, concrete, and composite. They are large material objects which have smaller material objects, including individual human beings, as parts. This view of social groups is not new, but it needs rehabilitating, having fallen out of favour since its heyday in and around the 1970s. In that period, such issues about groups featured in methodological debate about emergence, reductionism, and the relationship between sociology and individual psychology (Oppenheim and Putnam 1958, Quinton 1975-76, MacDonald and Pettit 1981, Mellor 1982). But in his landmark paper 'Social Wholes and Parts', David-Hillel Ruben articulated several decisiveseeming objections to the mereological view. He concluded: 'Whatever relations human beings bear to social entities, the relation of being a part of is not one of them' (Ruben 1983: 219). Ruben's paper, reinforced by his subsequent book on social metaphysics (1985), was dramatically effective. The mereological view became more-or-less invisible in the philosophical literature for a couple of decades.

More recently, the mereological view has begun to re-appear, primarily as a foil for alternative views. For example, Gabriel Uzquiano (2004) denies that social groups are sums, sets, or aggregates of people, arguing instead that they are sui generis entities constituted by sets, though not identical to sets. Nikk Effingham (2009) argues that social groups are sets of ordered pairs suitably involving worlds, times, and people. Katherine Ritchie (2013) denies that social groups are fusions, pluralities, aggregates, or sets; instead she argues that a group is a realization of a structure. Frank Hindriks (2013) argues for a 'non-reductive materialism' which uses resources from the metaphysics of material objects, but without simply identifying social groups with sums of people. Brian Epstein (2015) also works with the metaphysics of material objects, but again stops short of identifying groups with sums. 
Tobias Hansson Wahlberg (2014: 538) is an exception, endorsing the mereological view; he does not, however, rebut Ruben's arguments, since the main point of his paper lies elsewhere.

Why are these authors so set against the mereological view, or at best reluctant to advocate it in its most straightforward form? Ruben's paper richly deserved the long period of influence it has enjoyed. But in the intervening years since 1983 there has been a tidal wave of work in the metaphysics of composition, inspired by David Lewis, Peter van Inwagen, and others. We now have a much sharper, more detailed understanding of how to think clearly about parts and wholes. And in the light of that understanding, the mereological view of social groups should resume its position as a forerunner in debate.

In defending this view, I have two main tasks. I need to respond to objections raised by Ruben and others. And I need to offer some positive motivation for adopting the mereological view. It would be nice to have the motivation first, otherwise why care about the objections? But some of the positive reasons are easier to grasp once the objections have been dealt with. So I proceed as follows. After initial clarification of my terminology, I will briefly indicate some positive reasons for treating social groups mereologically. I will then respond to the various objections, thereby exhibiting the content and commitments of the mereological view. Finally, I will outline some consequences of the mereological view: these provide further arguments in its favour.

\section{Terminology and Scope}

Like Ruben, and the others mentioned above, I am concerned with the metaphysical nature of social groups and the metaphysical nature of the relationship between, for example, a reader and a book group, or a player and a cricket team. In ordinary contexts, we talk of clubs, 
committees and teams as having members, not parts: doesn't this usage immediately point us away from mereology, and towards set theory, with its ideology of membership rather than parthood? No: even for those who are in general inclined to draw metaphysical conclusions from ordinary language, ordinary usage here is too variable to be useful.

First, we use 'part', 'member', and 'one of' interchangeably to pick out this relation in ordinary contexts. For example, we can say that Ailsa is a member of the management team, part of the team, and one of the team. Now that we have got used to Ailsa's new husband Brian, we think of him as part of the family, one of the family, and a family member. And consider this authentic exchange: 'I'm a member of the Imperial Senate on a diplomatic mission to Alderaan!'; 'You are part of the Rebel Alliance and a traitor!'.

Second, we often use the language of membership - especially in commercial contexts without implying any kind of constituenthood, either mereological or set-theoretic. The members of a gym do not help compose or constitute it: they are just customers with contracts. The relationship between member and gym is like that between season-ticket holder and train company, customer and power company, subscriber and journal. (Things might be different if the gym were a collectively-owned cooperative of its members.) American Express has 'cardmembers', whilst Visa has 'cardholders', but this does not entail that Amex is larger than Visa: cardmembers are not constituents of American Express.

In short, ordinary usage of the terms 'member of', 'part of', and 'one of' in connection with social entities is too flexible to support one metaphysical view over another. For clarity, I will use the term 'constituent of' as a neutral way of referring to the relationship between e.g. reader and book group, or player and cricket team. Then the substantive question is whether 
the constituents of a social group are (set-theoretic) members of it, or (mereological) parts of it, or stand in some other relation to it.

Which collective social entities am I concerned with? I have mentioned committees, book groups, cricket teams, bands, crowds, populations, and social classes. Philosophical literature on group agency and group knowledge often also discusses corporations, governments, and scientific teams, whilst social scientists use terms like 'organisation' and 'institution' to draw important distinctions which are sometimes neglected by philosophers.

Several philosophers, including Ruben (1983), seem to find the mereological view more plausible for unstructured groups such as crowds, than for teams or committees. I will therefore focus on teams and the like, in order to demonstrate that the mereological view can handle the harder cases. Moreover, I will focus on social groups which are plausibly constituted by human persons alone, such as committees, teams, or book groups, rather than those, like businesses, which may seem to incorporate buildings and equipment; I will return to this issue in the conclusion.

\section{Motivation: Why Go Mereological?}

The debate about the metaphysical nature of social groups is not primarily a debate about what exists. All sides agree that the people now in the book group exist, and that the set of those people exists, alongside the set of ordered pairs of times and people who are in the book group at those times. Philosophers who deny that the group is the mereological sum of the people typically do not deny the very existence of that sum, not explicitly at least. Rather, the debate is about which entities have the various features normally attributed to social groups. Some metaphysicians, such as Uzquiano (2004), do propose new types of entity as social 
groups. But they do not deny the existence of the 'old' entities such as sets and composites; rather, they deny that such entities have the features normally attributed to social groups.

In this section I offer some initial positive reasons for thinking that social groups are concrete material particulars, and moreover that they have their constituents as parts. These are not supposed to establish the mereological view conclusively. Instead, they are reasons to take it seriously, even to regard it as the dialectical default, to be adopted unless there are strong arguments against doing so. Reflecting this default stance (as well as limitations of space), in the remainder of the paper I will defend the mereological view against objections, and offer some positive suggestions, but I will not attempt to generate new objections to rival views.

Why identify a social group with a concrete material particular? This identification helps us understand how a group can be embedded in the physical world, engaged in ordinary causal interactions with other groups, with individual people, and with non-human entities. We should recognise such interactions even if we believe that a group can cause (or be causally influenced) only if one of its constituents causes (or is causally influenced). This pattern is familiar at all levels of our multi-layered universe: we don't need to believe in spooky emergence to recognise that causation operates at the macroscopic level, even if this is philosophically puzzling. Being able to think sensibly about the causal features of social groups is important within the social sciences; it is also important for various philosophical debates about corporate agency, about causal and moral responsibility, and about varieties of social explanation. I do not suggest that such causal thinking is impossible if groups are not concrete particulars, but identifying them as such certainly simplifies the picture. 
Identifying a social group with a concrete material particular also makes it easier to understand how one and the same entity - the social group - can have both mundane physical features and exciting social features. A book group fits into the kitchen and makes enough noise to wake up the baby. The very same group is a source of social prestige within the village and is a reason why the library is still well-used: there does not seem to be any referential shift when we say that the book group is both noisy and prestigious. It is possible to account for the apparent physical features of social groups without identifying them with concrete particulars, but the account is straightforward if we do make that identification.

Supposing that we do identify social groups with concrete material particulars, there are several reasons to regard their constituents (their 'members') as amongst their parts. It is clear that many group features are at the very least partially determined by the features of their members, even if they are not fully reducible. And the part-whole relation paradigmatically supports such correlations between smaller and larger material objects. Moreover, the large literature on material objects, parthood and composition provides us with lots of different models for thinking about these issues, whether our tastes incline QuineishLewisly, Fineish-hylomorphically, or otherwise (I return to these possibilities below).

So there are good reasons for at least trying to make sense of social groups as concrete material particulars composed of human beings. I will now consider the objections which have been raised against the mereological view of social groups.

\section{Objections from Temporal and Modal Flexibility}

Many social groups change their constituents over time, as people come and go; formal groups with membership rules typically make explicit provision for this. Counterfactually, 
many social groups would have had different constituents, if different people had joined. (Many, not all: perhaps some groups have their founding members essentially, Kripke-style.) These ordinary facts might seem to present a problem for the mereological view of social groups. After all, the term 'mereological' can evoke the full magnificent force of classical extensional mereology, including unrestricted composition (the existence of arbitrary sums), and extensionality of composition (no distinct objects with the exact same parts). It may also suggest mereological essentialism, and/or temporal inflexibility. For example, Effingham (2009) refers to the mereological view of social groups as 'fusionism', i.e. the view that social groups are fusions of their members, and Ritchie (2013) also uses this term. A fusion is often taken to have its parts both essentially and permanently.

Although I will discuss some of these strong claims about parthood and composition later in the paper, I am not committed to them by my use of the term 'mereological'. After all, it is obvious that many ordinary concrete objects - organisms, artifacts, mountains - also change their parts across time and across worlds. Admittedly, this flexibility generates metaphysical puzzles, prompting different accounts of material constitution, persistence through time, and identity across possible worlds. But nobody thinks that such flexibility trivially shows that, for example, organisms do not have their cells, limbs and organs as parts, i.e. that the relationship between cell and organism is not mereological.

So I use the term 'mereological' to indicate that the relationship between constituent and group is one of parthood, rather than, for example, set-membership. Thus 'mereological' here does not mean 'conforming to classical extensional mereology and mereological essentialism'. This is a terminological clarification, but it is not a superficial point. Without such clarification we risk drawing up an incomplete list of possible accounts of social groups: 
when thinking about the relationship between a social group and its individual constituents, we are not forced to choose between set-membership, parthood as understood in line with classical extensional mereology and mereological essentialism, or a sui generis relation. There is also the option of a more ordinary-looking and flexible parthood relation. (Hansson Wahlberg (2014) explores issues of temporal persistence for social groups.)

\section{Objection from the Transitivity of Parthood}

The transitivity of parthood is often invoked against a mereological view of social groups. For example, Simon le Bon is a member of once-popular British band Duran Duran. According to the mereological view, Simon is thus part of Duran Duran. Now, Simon's nose is a part of Simon, so, by the transitivity of parthood, Simon's nose is part of Duran Duran. This consequence of the mereological view is widely thought to be problematic: surely Simon has a special status within Duran Duran, a status which his nose lacks? We could avoid the problematic consequence by denying the transitivity of parthood, but this would be a high price to pay.

Ruben (1983: 231-2) articulates a version of the transitivity argument, and it is invoked by several recent authors. For example, Uzquiano writes:

The Supreme Court seems not to be a material object or a mereological fusion of them, since membership in the Supreme Court is very different from the part-whole relation on material objects. The part-whole relation on material objects is a transitive relation. Thus if one identified the Supreme Court with a material object and Justice Breyer with a part of it, then one would be forced to conclude that Justice Breyer's arm must be a part of the Supreme Court as well. Yet, it is plain that Justice Breyer's arm is neither a part nor a member of the Supreme Court. (2004: 136-7) 
It is certainly plain that Breyer's arm is not a member of the Supreme Court, just as Simon's nose is not a member of Duran Duran. For example, Breyer's arm does not have voting rights, and Simon's nose does not get its own share of the royalties. But it is not just plain that arms and noses are not parts of the Supreme Court or of Duran Duran. If we asked how many arms were parts of the Supreme Court, we'd get a peculiar look, but 'eighteen' is currently the most plausible answer, not 'none'.

The fact that we can make sense of this question does not count strongly in favour of the mereological view: I have already pointed out that ordinary usage is highly variable. But it shows that it is far from plain that Breyer's arm is not part of the Supreme Court. The transitivity argument is weak if read only as an appeal to ordinary intuitions.

Isn't there a more powerful reading of the transitivity argument? After all, there is an undeniably important difference between Breyer's relation to the Supreme Court and Breyer's arm's relation to the Supreme Court. And the mereological account seems to ignore this important difference. Here, for example, is Epstein discussing Uzquiano, in connection with a different judge:

[I]t does not seem right to say that Samuel Alito's right arm is one of the parts of the Supreme Court. (Or, at least, if Alito's right arm does count as a part of the Supreme Court, then 'parthood' is not the relation we are interested in. Rather, the relevant relation is that Alito is a member of the Supreme Court - and Alito's arm is certainly not that.) (2015: 144) 
Uzquiano, Epstein, and others assume that an account of the general metaphysical nature of social groups - as composite material objects, say, or as sets, or as pluralities - should provide an account of the difference between Alito's relation to the Court and Alito's arm's relation to the Court. The mereological view is supposedly inadequate because it does not account for this difference.

But this is no inadequacy. The mereological view allows for the differences between Alito and Alito's arm to be explained by constitutional lawyers, rather than metaphysicians. And that is as it should be. Consider an analogy. My dog is a material object, with parts including its molecules, cells, organs, and limbs. What is the difference between those parts which are organs, and those which are not? Presumably, an organ stands in some distinctive relation to the whole dog, different from the relation between e.g. a molecule and the dog. But this is an issue for physiologists, not metaphysicians: we do not expect the differences between canine organs and other canine parts to correspond to a deep metaphysical distinction between two different ways of being a dog constituent, as different as parthood and set-membership. Likewise, the role of the individual bricks within a Lego model is distinctively different from the role of the individual molecules within that model - anyone who failed to understand this would struggle to enjoy Lego - but we regard both bricks and molecules as parts.

So why do Ruben, Uzquiano, Epstein, and others expect a metaphysical account of the difference between Alito and Alito's arm in respect of the Supreme Court? Effingham helpfully spells out the expectation as an explicit desideratum. In his terminology, 'membership ${ }_{\mathrm{G}}$ ' is the relation between group member, i.e. constituent, and group, and so he articulates the desideratum thus: 'Primitives (P): Membership ${ }_{\mathrm{G}}$ should be analysable (using familiar terms)' (2009: 253). 
Effingham suggests that a theory which does not satisfy desideratum $(\mathrm{P})$ must instead regard group membership as a primitive; this echoes Lewis on the profound but inescapable mystery of the relation between an individual and its singleton set (Lewis 1991). Effingham introduces (P) in the context of Uzquiano's claim that social groups are sui generis; Uzquiano does indeed seem to treat group membership as a primitive.

But Effingham then wields $(\mathrm{P})$ against the mereological view, saying that:

[the mereological view] fares badly with regards to desideratum (P). The only analysis of membership ${ }_{G}$ appears to be $\mathrm{x}$ is a member $_{\mathrm{G}}$ of group $\mathrm{g}$ at time $\mathrm{t}=_{\mathrm{df}} \mathrm{x}$ is a part of $\mathrm{g}$ at $\mathrm{t}$ But the transitivity of parthood ruins this (Uzquiano 2004: 136-7). Given groups are fusions, not only the footballers but all of their parts (lungs, kidneys etc.) will (wrongly) turn out to be members $\mathrm{G}$ given this definition. (2009: 255)

The mereological view offers a necessary condition for membership : if $\mathrm{x}$ is a member mof $_{\text {group }} \mathrm{g}$ at time $\mathrm{t}$, then $\mathrm{x}$ is a part of $\mathrm{g}$ at $\mathrm{t}$. The view does not offer necessary-and-sufficient conditions, so a fortiori it does not offer an analysis. But this doesn't mean that membership ${ }_{\mathrm{G}}$ is taken to be primitive or mysterious. Instead, the features which distinguish those parts which count as members from those parts which do not count as members will be ordinary natural and social facts, different ones in different cases.

Analogously, according to the completely uncontroversial mereological view of dogs: if $\mathrm{x}$ is an organ of dog $\mathrm{d}$ at time $\mathrm{t}$, then $\mathrm{x}$ is a part of $\mathrm{d}$ at $t$. 
The features which distinguish those parts which count as organs from those parts which do not count as organs will be ordinary physiological facts. We do not regard 'being an organ of' as primitive or mysterious.

So what does determine which amongst the parts of a group are its members? It varies, but here is an example. The Institute of Philosophy (IP) in London offers membership both to individual philosophers and to philosophy departments of UK universities. Professor Gromit is a member of the Department of Philosophy at the University of Wensleydale, and the Wensleydale department is a member of the IP. Is Professor Gromit a member of the IP, in virtue of his being a member of a member of the IP? We do not try to answer this question by considering the metaphysics of social groups. Instead, we consult the website of the IP, where we find that members of institutional members are not automatically members of the IP; evidently, the IP could have adopted different regulations, rendering membership transitive.

Given the mereological view of social groups, the Wensleydale department is part of the Institute of Philosophy, and so is Professor Gromit, since he is part of the Wensleydale department. The department is a part which is a member of the IP, whilst Professor Gromit is a part which is not a member; so is Gromit's nose. This distinction makes for differences in powers and obligations, perhaps in voting rights or subscription fees. But what these differences are, and, more generally, the distinction between member-parts of the IP and nonmember-parts of the IP, is determined by the contingent details of the IP constitution. The mereological view does not entail that membership of the Institute of Philosophy is some kind of metaphysical primitive. 
The possibility of institutional membership also shows that we cannot identify membership ${ }_{G}$ with being-a-part-and-a-human-being. The Wensleydale department is a member $_{G}$ of the Institute of Philosophy; moreover Effingham suggests that an animal mascot might be a member $_{\mathrm{G}}$ of a sports team. Conversely, Professor Gromit is a human being and a part of the Institute of Philosophy without being a member $_{G}$ of the IP. (Ruben also discusses institutional membership in connection with transitivity (1983: 231).)

For legally-established groups such as the IP, membership and parthood are determined by formal rules. But the same metaphysical picture also captures informal groups, though lack of formality sometimes generates indeterminacy. Barbara is part of a book group, so her nose is a part of the book group; Barbara is a member, her nose is not. Twins Charlie and Danny Erskine are parts of the book group, but never attend simultaneously because one stays home to dog sit; they share a single copy of the book, and pay only one share of the group's birthday gift for the host. Are Charlie and Danny both members, or is their sum - the Erskine twins - a single member of the group? The group could decide to resolve it either way.

I conclude that the transitivity-of-parthood argument against the mereological view demands a general metaphysical account of something which is in fact grounded for different groups in different ways, by a range of natural and social facts. Much philosophical work in 'social ontology' or 'social metaphysics' is aimed at understanding how certain entities, including groups, acquire a variety of social statuses, and the relationship between this process and our attitudes, laws, conventions, and so on. This is an entirely proper aim for social metaphysics, and is undiminished by the recognition that the membership conditions of a given group are primarily a matter for empirical or legal investigation. Understanding social groups as 
concrete particulars, with people amongst their parts, does not close down other metaphysical or empirical investigations, but puts them on a firmer footing.

\section{Objection from Coextensional Groups}

Another influential accusation is that the mereological view supposedly cannot accommodate distinct social groups which share all their members. Examples of such coextensional groups include: a family and a theatrical troupe; a ruling class and a caste (both Ruben 1983: 235); the board of the Massachusetts Department of Transportation (MassDOT) and the board of the Massachusetts Bay Transportation Authority (MBTA) (Epstein 2015: 139); the Supreme Court and the (hypothetical) Special Committee on Judicial Ethics (Uzquiano 2004: 141); a chess club and a nature club (Ritchie 2013: 258).

Coextensional groups have different purposes, powers, and duties, and they typically meet at different times. For example, suppose the MassDOT board meets on Mondays, and the MBTA board on Tuesdays. This suggests a Leibniz's Law argument: the MassDOT board meets on Mondays, the MBTA board does not meet on Mondays, thus the MassDOT board is not identical to the MBTA board. Some coextensional groups could easily have differed in their members. Others are necessarily coextensional, perhaps where committee members are appointed ex officio. And, whilst the typical examples concern two coextensional groups, we can easily imagine three or more coextensional groups.

Why are coextensional groups supposed to be problematic for the mereological view of social groups? Ritchie, like Effingham, refers to the mereological view as 'fusionism', and says 'the identity conditions of groups when they are taken to be fusions are extensional' (2013: 263). If we accept an extensional mereology, then indeed the mereological view cannot 
permit coextensional distinct groups. So advocates of the mereological view have two options. We can develop a nonextensional mereological view. Or we can stick with extensional mereology, insisting that coextensional groups are identical after all, and try to disarm the Leibniz Law arguments.

This is reminiscent of debates about the infamous statue and lump, which apparently share all their parts. Almost everyone has a mereological view of statues and lumps, i.e. we regard them as composite objects. So we have two options there. We can develop a nonextensional mereology which allows for distinct objects to share all their parts. Or we can stick with extensional mereology, insisting that statue and lump are identical after all, and try to disarm Leibniz's Law arguments based on apparent differences between statue and lump. Exploring variants on these two strategies has generated a huge literature, usefully summarised by Wasserman (2017). How might these strategies work out for groups?

There has been some investigation of nonextensional mereologies for social groups. Epstein (2015: 144-49) explores how the literature about statues and lumps can help us understand the possibility of distinct yet coextensional groups. Ritchie (2013: 264) discusses counterpart theory in this context, and Hindriks (2013) also suggests a 'constitution' view, which I discuss below in section 7. Philosophers who are independently committed to distinguishing the statue from the lump can adopt a similarly nonextensional mereology of social groups.

However, those who are not already committed to nonextensional mereology should insist that coextensional groups are identical, rather than making a special exception for groups. I first explain what it means to identify coextensional groups, before discussing how best to respond to Leibniz Law arguments against this identification. 
On either an extensional or a nonextensional mereological view, the MassDOT board is a material object composed of human beings, and so is the MBTA board. Endorsing extensionality means regarding the MassDOT board and the MBTA board as a single composite object playing two different social roles. We are familiar with cases in which a single human being plays two such roles. For example, during most of 2015 Boris Johnson was both Mayor of London and Member of Parliament for Uxbridge and South Ruislip. The role of Mayor and that of MP are mutually independent, associated with different powers and responsibilities. Johnson was elected Mayor in 2008, was elected to Parliament in 2015, and completed his term of office as Mayor in 2016.

During 2015-16, the Mayor of London and the MP for Uxbridge are not two distinct entities each constituted by Boris Johnson. Rather, they are but a single Boris-shaped entity. The Mayor is human, all too human: he has weight, height, and spatial location, and he is fiftyone years old. Ditto the MP. Johnson does not merely constitute the Mayor, or the MP: these three are one. It is a tricky question as to when Johnson is acting or speaking as Mayor, when as MP, and when as a private individual; his opponents are quick to seek out unclarities and potential conflicts of interest. The multiple roles create political, ethical, and timemanagement challenges, but they do not generate a metaphysical conundrum.

Similarly, given the extensional mereological view of social groups, the MassDOT board and the MBTA board are one and the same material object. Compared to Boris Johnson, there is less potential for public confusion about when this entity is acting or speaking as the MassDOT board, and when as the MBTA board, since this is determined by explicit constitutional rules. Nevertheless, there is no fundamental difference between the two cases. 
The phenomenon of coextensional groups is the collective version of something very familiar: the single person who fills more than one social role.

What are social roles, and what determines how they are filled? These are excellent and tricky questions, rightly the subject matter of much work in social ontology and the social sciences. But they can be asked about individuals just as they can be asked about committees and other groups; there is no distinctive problem which arises in the group context and not for individuals.

Now, what about Leibniz's Law? After all, the MassDOT board meets on Mondays, and the MBTA board does not meet on Mondays. Similarly, the Mayor answers questions in the London Assembly, whilst the MP for Uxbridge does not. (Likewise, it may be argued, the statue is Romanesque whilst the lump of clay is not; Fine 2003.) Yet Leibniz's Law tells us that if objects are one and the same thing, they cannot differ in their properties.

Ofra Magidor (2011) explores possible responses to arguments from Leibniz's Law across an array of philosophical contexts, though she does not discuss social groups specifically. For example, using the predicational shift response we may claim that the same predicate ('meets on Mondays') invokes different properties when attached to different singular terms. It is true that the MassDOT board meets on Mondays, and that the MBTA board doesn't meet on Mondays. But if this involves predicational shift, then no single property is being first attributed and then denied. A certain concrete entity meets-as-the-MassDOT-board on Mondays, and that very same entity doesn't meet-as-the-MBTA-board on Mondays (Fine 2003). Likewise, Boris answers-questions-as-Mayor in the London Assembly, and doesn't 
answer-questions-as-MP in the London Assembly, again without incoherence since two different predicates are involved.

Predicational shift is an especially plausible diagnosis in social cases, even for those who doubt its capacity to explain all seeming differences between statues and lumps. After all, we are very familiar with notions such as meeting-as, speaking-as, and attending-as. Speaking as your colleague, I say you should work all weekend, but speaking as your friend, I say you should take some time off. Such situations are socially complex, often difficult to navigate. And they raise important theoretical questions as to what determines who plays which role, and which powers and responsibilities are associated with such roles. Nevertheless, these complexities do not typically prompt us to deny that I am both your colleague and your friend, or that Boris Johnson is both Mayor and MP.

Of course, what I say here does not fully vindicate the predicational shift diagnosis, which is explored at much greater length by Magidor and others. But for those who are sceptical, diagnosing a predicational shift, an ambiguity in 'meets on Mondays', is not the only option if we want to identify coextensional groups; again, Magidor (2011) lays out the possibilities.

It is true that the MassDOT board meets on Mondays. So we might say that, despite initial judgements, it is also true that the MBTA board meets on Mondays. The initial judgement is explained away on the grounds that it is pragmatically infelicitous to utter that truth expressed in those terms, since it would suggest, falsely, that the MBTA board conducts MBTA business on Mondays. The analogous line regarding Boris Johnson would be that it was true to say in 2015 that the MP for Uxbridge answers questions in the London Assembly, but it 
was pragmatically infelicitous to say so in those terms, since it would have falsely suggested that he answered questions about his work for the constituents of Uxbridge in that forum.

If you can't stomach any of the options available to an extensional mereological account, the alternative is to distinguish Mayor from MP, and MBTA board from MassDOT board. Perhaps these are distinct material entities, constituted by their members or parts in nonextensional ways; Epstein (2015) suggests something like this picture of the MBTA board and the MassDOT board But an advocate of this kind of non-extensional account of social groups seems also committed to the unattractive idea that the Mayor and the MP are two distinct material objects, each distinct from Boris Johnson but occupying the same location as him throughout 2015. After all, insofar as we have reason to distinguish the two boards, we have equally strong reason to distinguish the two individual office-holders. This threatens to generalise still further, leading us to distinguish husband from father, friend from colleague, or student from volleyball player.

Perhaps then Mayor, MP, MBTA board and MassDOT board are not material objects, but are instead abstract entities of some kind, instantiated by different material objects at different times. The availability of an attractive extensional mereology of groups means that nominalists who otherwise reject abstracta should not make an exception in this case. But many metaphysicians accept abstract entities, structures or properties into their ontology for various reasons independent of social groups; for such philosophers, the issue is not whether the abstract role corresponding to the Mayor of London exists, but whether that abstract entity has the properties normally attributed to the Mayor. 
I will not attempt to argue that abstracta cannot make budget decisions or attend meetings: my strategy in this paper is to motivate the view that groups are material objects with human parts, and to defend that view against objections, rather than to launch objections against rival views. But again I note whatever reasons we may have for treating the MBTA board and the MassDOT board as abstract entities extend to entities like the Mayor and the MP, and potentially even further. That is to say, the shift from one to many people does not generate new problems of material coincidence.

There are important questions about what social roles are, and about how we inhabit and negotiate our sometimes-conflicting social roles. Nevertheless, there is nothing special about groups as opposed to individuals in this regard: just as we recognise that human individuals like Boris Johnson are material objects playing social roles, likewise we should recognise that sums of human individuals are material objects which can play social roles.

A final detail about coextensional groups. Given this mereological view, groups which share all their members thereby share all their parts, and are one and the same material object. However, when institutional membership is possible, then groups can share all their parts without sharing all their members. Suppose that (i) all and only haberdashers are members of the Haberdashers' Union; (ii) all and only local chapters of the HU are members of the Congress of Haberdashers' Union Chapters; (iii) all and only the members of the HU are members of chapters which are members of the CHUC. Then the HU and the CHUC are the same material object, having the same parts, but they have different members (the HU has only individual members, the CHUC has only chapter members). 
This suggests another Leibniz's Law argument: Harry is a member of the HU, he is not a member of the CHUC, thus the HU is not identical to the CHUC, contrary to the extensional mereological account. But again responses are available: for example, by citing predicational shift, that 'being a member of the HU' corresponds to a different property than does 'being a member of the CHUC' even though the HU and CHUC are one and the same object. This coheres with my earlier point that, although every group-membership relation involves parthood, what is additionally required for membership may differ from group to group, determined by formal rules of constitution for groups like the HU and the CHUC. Again, we may wonder how the HU and the CHUC can have different constitutions, if they are one and the same material object, but again we should recall that we may ask analogous questions about the Mayor and the MP.

\section{Objection from Group Location}

Ruben (1983) influentially argued that an organisation may have a location which differs from the location of any sum of people. The International Red Cross can be located in places where no person is located (e.g. in its headquarters outside working hours), and it can fail to be located in places where the people associated with it are located (e.g. in its employees' homes outside working hours). Thus, seemingly, the International Red Cross cannot be identified with any sum of people, and the mereological view is false for organisations of this kind.

The location argument is another instance of Leibniz Law reasoning, this time used to distinguish a social group from the sum of its members, rather than to distinguish one social group from another. The social group and the sum of the members appear to differ in their location, thus they are apparently distinct. I will defend the mereological view, the claim that 
the social group is identical to the sum of the members, by arguing that there is no genuine difference between the group and the sum.

Consider an individual, rather than a group. An individual person has an official location, possibly several, for purposes of local or national taxation, voting, census, school enrolment, and so on. For some of these purposes, the official location is supposed to correspond to the person's current, predominant, or habitual physical location, but the relationships are not straightforward. For example, you can vote by post if you are absent from your place of voter registration on election day (thereby voting in a district without being located in it); you can be liable for taxes in more than one place simultaneously; the status of military personnel serving overseas is especially complex.

What to make of all this? It doesn't cross our minds to imagine there is a single located-at relation which relates various different entities - the tax-payer, the voter, the school applicant - to various different spatial points. Instead, we realise that there is a single entity - the human person in question - who is located at a smallish spatial region at any given moment, and who also stands in a variety of different historical-social-legal relations to different spatial regions or points.

The same attitude works for social groups: rather than multiplying entities, we should recognise a multiplicity of relations between a single entity and a variety of spatial regions. A single organisation might have different official locations for different official purposes, for example filing of accounts, employment regulation, or registration with professional bodies. Like an individual, an organisation might have two locations for a single purpose, for example being liable for tax in two different places. This is all compatible with the claim that 
the social group is a material object which occupies the unique region which is the sum of the regions occupied by the individual people making up the group.

Frank Hindriks (2013) discusses Ruben's location argument, whilst advocating his own distinctive social ontology:

Constitution is commonly seen as a relation between two entities that are spatially coincident but non-identical. I suggest that organizations can have institutional locations that need not coincide with the physical location of the people that constitute them. This fits nicely with the thesis that constitution is distinct from identity. However, it conflicts with the assertion that constitution requires spatial coincidence. I argue that this requirement is inadequate for organizations...the institutional location of an entity need not coincide with its physical location, or, more precisely, with the location of the object(s) that constitute it. (2013: 415)

Hindriks may be thinking of constitution as a many-one relation between the several people and the organisation: the people have physical locations and the organisation has an institutional location, though it is unclear whether the organisation also inherits a physical location from the people. On this reading, Hindriks endorses something like a mereological view of groups, later supplemented by a rich account of agency, enactment, and status.

Alternatively, perhaps Hindriks is thinking of constitution as one-one non-identity relation between the sum of the relevant people and the organisation: the sum has its physical location, and the organisation has an institutional location, although again it is unclear whether the organisation also has a physical location, inherited from the sum. This is the view I reject, since location considerations do not drive us to special metaphysical measures in either the group or the individual case. We do not think that a human being constitutes a 
tax-payer with whom she fails to spatially coincide, even when the human being is absent from the place in which she pays tax.

Why does it seem to Ruben (and possibly to Hindriks) that the official or institutional location of a social entity must literally be the location of something, whereas nobody has been tempted to think that the 'taxpayer location' of a person is literally the location of something? Perhaps it is because the powers and responsibilities which an organisation exercises in connection with its official location(s) are typically its most salient features. In contrast, whilst we realise that individual human beings pay tax and vote, in many contexts their physically-localised features are most salient to us. One might speculate, however, that the coming ubiquity of telecommunications and 'telepresence' will eventually shift the balance in our thinking about individuals too.

\section{Conclusions and Next Steps}

In section 3, I offered some reasons for taking social groups to be concrete material particulars, and for taking the members of such groups to be amongst their parts. I have now shown that the standard objections to this view are unsuccessful. The details depend on the objection, but two recurring themes have emerged.

First, objectors often overlook the ways in which social groups are distinctive because they are social, not because they are groups; it is easy to miss the fact that a single individual can be distinctive in the same social ways. That is, the primary sense in which social groups are 'social' is not that they contain multiple people. Rather, it is that they have social significance: for example they often have legal status, they typically have key properties in virtue of the attitudes of both members and non-members, and so on. In this same sense, 
each of us is a social individual, with legal capacities and obligations, instantiating many important properties in virtue of our own attitudes and those of others. Indeed, inanimate objects - and 'groups' thereof, such as a museum collection - can also have social statuses of various kinds. The sources, persistence and structure of this social world are the central topic of much work in social metaphysics beyond the literature on the nature of groups. And my argument that groups are concrete objects with their members amongst their parts is not intended to supplant that broader work in social metaphysics, which applies to individual people, to groups of people, and to other entities.

As I discussed in sections 6 and 7, an individual person can simultaneously fulfil several different social roles, and have several different 'official' locations. It is not always obvious how to understand these individual phenomena, either metaphysically or semantically. But it is obvious that, somehow or other, we can account for them without denying that people are concrete material objects with lots of interesting social features. Likewise, we can account for the interesting social features of groups without denying that groups are concrete material objects.

A mereological view of social groups renders such groups commensurable with social individuals (i.e. all of us), but also with 'mixed' social entities which are partly constituted by inanimate objects, partly by people. Following the predominant emphasis of the literature, I have focused on social groups which seem to be wholly constituted by the people, or groups of people, who are their members. However, Epstein (2015) reminds us that many collective social entities - including corporations and universities - seem to be partially constituted by buildings and equipment. (Or, more cautiously, facts about buildings and equipment form a major element of the supervenience basis for facts about corporations and universities.) 
Likewise Bird (2010) emphasises the epistemic significance of e.g. libraries and artefacts in constituting group knowledge.

Given a mereological view of social groups, we can distinguish an object which is composed of all the people who help constitute a corporation or university, from a larger object which is composed of those people together with the buildings, equipment and so on. These are two composite material particulars, each a candidate referent for our talk about the corporation or university in question. This gives us a flexible metaphysical framework within which to discuss whether, for example, a social collective might begin as wholly constituted by people, before coming to incorporate non-personal entities.

A second recurring theme in criticism is that objectors often attack an implausible version of the mereological view, for example lumbering it with mereological essentialism. In my view, we can argue for a mereological view of social groups, then go on to discuss how best to think about the relevant relations of parthood and composition: for example, is composition extensional, is it unrestricted? I made a start on this project in defending an extensional account of 'coextensional groups' such as the MBTA board and the MassDOT board.

After all, this is our standard approach to the metaphysics of parts and wholes for ordinary material objects: we begin by adopting a broadly mereological approach, i.e. accepting that ordinary objects have other ordinary objects as parts, then go on to discuss how best to think about the relevant relations of parthood and composition. There is a deep question about how to distinguish parthood relations from non-parthood relations if we do not anchor parthood in a formal framework such as classical extensional mereology. But that question does not arise in any distinctive way with respect to the metaphysics of social groups, as opposed to 
ordinary material objects. There is no special reason why a mereological view of social groups should adopt otherwise-implausible principles about parthood and composition.

As I remarked in section 3, an advantage of the mereological view is that it enables us to draw on the vast existing literature about parthood, composition, and the persistence of material objects, in order to help us understand social groups. My own tastes encompass four-dimensionalism, unrestricted composition, and extensionality. Although I cannot defend these views here, much of what makes them attractive with respect to ordinary material objects also applies with respect to social groups understood mereologically. For example, on this picture, there are vast numbers of overlapping social groups, with varied spatial and temporal boundaries; which of these we talk about in ordinary contexts is determined by a combination of natural facts and our interests and conventions; attempted reference to particular social groups will often suffer semantic indeterminacy, but this indeterminacy can be tamed using supervaluational strategies. (The papers in Loewer and Schaffer (eds.) (2015) cover many of these issues as applied to ordinary individuals; Hawley and Bird (2011) discuss universals and natural kinds in this framework.)

However, very different accounts of parthood, composition and persistence for material objects can also be fruitfully applied to social groups, once those are understood mereologically. To take a recent example which stands in an ancient tradition, Simon Evnine (2016) understands material objects in terms of matter and form, taking a 'top-down' approach to the unification of material parts in an organism or artifact. As applied to social groups, this suggests a less abundant picture of the social world, with groups formed out of material persons in ways which are underpinned by functions or intentions. One attractive 
feature of this picture is that it assimilates at least some social groups to artifacts, and relates group-formation to social life more generally.

Adopting a mereological view of social groups does not resolve all outstanding philosophical questions in this area, and the view can be developed in a variety of different metaphysical traditions. But the mereological approach provides firm foundations for future work, whether metaphysical, social scientific, ethical, or political. The usual objections to the mereological view are unsuccessful, and it is time to set them aside.

\section{Acknowledgements}

Work on this paper was supported by a Leverhulme Major Research Fellowship, which I gladly acknowledge. I gave talks about social groups at the 2015 conference of the OZW Dutch Research School in Philosophy, at the 2016 Arché reading party, and at the Royal Institute of Philosophy in 2017, and received very helpful feedback on all these occasions. In addition, I thank Alexander Bird, Aaron Cotnoir, Aisling Crean, Frank Hindriks, Annina Loets, David-Hillel Ruben, and Gabriel Uzquiano for comments and discussion; I am also grateful to the anonymous referees who read this paper. 


\section{References}

Bird, Alexander (2010) 'Social Knowing: the Social Sense of "Scientific Knowledge". Philosophical Perspectives, 24,23-56.

Effingham, Nikk (2010) 'The Metaphysics of Groups'. Philosophical Studies, 149, 251-267. Epstein, Brian (2015) The Ant Trap. New York: Oxford University Press.

Evnine, Simon J. (2016) Making Objects and Events: a Hylomorphic Theory of Artifacts, Actions and Organisms. New York: Oxford University Press.

Fine, Kit (2003) 'The Non-Identity of a Material Thing and Its Matter'. Mind, 112, 195-234. Hansson Wahlberg, Tobias (2014) 'Institutional Objects, Reductionism and Theories of Persistence'. Dialectica, 68.4, 525-562.

Hawley, Katherine and Bird, Alexander (2011) 'What are Natural Kinds?' Philosophical Perspectives, 25.1, 205-221.

Hindriks, Frank (2013) 'The Location Problem in Social Ontology’. Synthese, 190, 412-437. Lewis, David (1991) Parts of Classes. Oxford: Basil Blackwell.

Loewer, Barry and Schaffer, Jonathan (2015) A Companion to David Lewis. Hoboken NJ: Wiley-Blackwell.

MacDonald, Graham, and Pettit, Philip (1981) Semantics and Social Science. London: Routledge \& Kegan Paul.

Magidor, Ofra (2011) ‘Arguments By Leibniz’s Law in Metaphysics'. Philosophy Compass, $6.3,180-195$

Mellor, D.H. (1982) 'The Reduction of Society'. Philosophy, 57, 51-75.

Oppenheim, Paul and Putnam, Hilary (1958) 'Unity of Science as a Working Hypothesis'. Minnesota Studies in the Philosophy of Science, 2, 3-36.

Quinton, Anthony (1975-76) 'Social Objects'. Proceedings of the Aristotelian Society, 76, 127. 
Ritchie, Katherine (2013) 'What Are Groups?'. Philosophical Studies, 155, 257-272.

Ruben, David-Hillel (1983) 'Social Wholes and Parts'. Mind, 92, 219-238.

Ruben, David-Hillel (1985) The Metaphysics of the Social World. London: Routledge \& Kegan Paul.

Uzquiano, Gabriel (2004) 'The Supreme Court and the Supreme Court Justices: a Metaphysical Puzzle'. Nô̂s, 38.1, 135-153.

Wasserman, Ryan (2017) 'Material Constitution'. In The Stanford Encyclopedia of Philosophy (Fall 2017 Edition), Edward N. Zalta (ed.) URL = $<$ https://plato.stanford.edu/archives/fall2017/entries/material-constitution/>. 